\title{
Corpse removal increases when honey bee colonies experience high Varroa destructor infestation
}

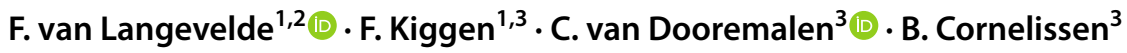

Received: 13 June 2020 / Revised: 29 September 2020 / Accepted: 21 October 2020 / Published online: 5 November 2020

(c) The Author(s) 2020

\begin{abstract}
High parasite load may increase honey bee mortality, which enhances stimuli for undertaker recruitment in colonies due to the presence of more corpses. However, it is unknown whether colonies exposed to the parasitic mite Varroa destructor ( $\mathrm{V}+$ colonies) remove corpses faster compared to colonies with reduced parasite levels ( $\mathrm{V}$ - colonies). To test this hypothesis, different amounts of dead bees ( 25 or 100) were added to V+and V- colonies to increase undertaker's workload and to monitor the colonies' undertaking performance (number of corpses removed after fixed time intervals and time until task completion). Until $40 \mathrm{~min}$ after adding corpses, $\mathrm{V}+$ colonies had removed more corpses compared to $\mathrm{V}-$ colonies, especially when 100 corpses were added. At $100 \mathrm{~min}$ after adding the corpses and onwards, the difference between the V+and V-colonies disappeared. $\mathrm{V}+$ colonies used less time until task completion, especially when challenged to remove 25 corpses. The first efficient undertaking response in $\mathrm{V}+$ colonies may have been caused by more or more experienced undertakers on standby compared to $\mathrm{V}$ - colonies, resulting in less total time needed to complete their undertaking task at increased workload. Our study suggests that changes in the division of labour in $\mathrm{V}+$ colonies were not impaired, but we cannot exclude long-term effects for the colony as time spent on undertaking cannot be spent on other tasks. Our study contributes to understanding of social resilience in colonies under high stress and exposed to immediate emergencies.
\end{abstract}

Keywords Undertaking $\cdot$ Division of labour $\cdot$ Task performance $\cdot$ Stress $\cdot$ Parasites $\cdot$ Social resilience

\section{Introduction}

Social insects have sophisticated mechanisms to help suppress pathogens and parasites to maintain a healthy colony, such as social immune responses and behavioural adaptations (Wilson-Rich et al. 2009; Evans and Spivak 2010; Sun and Zhou 2013). In honey bees (Apis mellifera), altruistic suicide (Ruepell et al. 2010), grooming (Boecking and Spivak 1999; Kruitwagen et al. 2017), removal of infected brood (Panziera et al. 2017) and corpse removal (Visscher

F. van Langevelde

frank.vanlangevelde@wur.nl

1 Wildlife Ecology and Conservation Group, Wageningen University and Research Centre, Droevendaalsesteeg 3a, 6708 PB Wageningen, The Netherlands

2 School of Life Sciences, Westville Campus, University of KwaZulu-Natal, Durban 4000, South Africa

3 Bees@Wur, Wageningen University and Research Centre, Droevendaalsesteeg 1, Wageningen 6708 PB, The Netherlands
1983; Sun and Zhou 2013) are found to prevent spread of pathogens and parasites. Removal of corpses from the nest (undertaking) is critical for colony hygiene in enclosed nests, although it is performed by only a small percentage (1-2\%) of the colony's workers (Visscher 1983; Moore et al. 1987; Breed et al. 1990).

Corpse removal is part of the division of labour (DOL) among the workers in a colony (Visscher 1983; Trumbo et al. 1997) and is influenced by both age polyethism and genetic variation. The corpse removal task is performed by a genetically distinct group among the middle-aged bees (MABs) as workers from some subfamilies are relatively more likely to act as undertakers than others (Robinson and Page 1988, 1995). DOL in honey bees (also in other social insects) is often explained by the response threshold model (Robinson and Page 1988; Bonabeau et al. 1996; Duarte et al. 2012). A threshold for a particular task is the amount of stimuli that is needed for workers to perform the task. A higher threshold requires stronger stimuli, which translates into less preference for performing this task. As the demand for a task increases, thresholds for a higher proportion of 
workers are met and more workers are allocated to that task. Hence, colonies respond to changing internal and external conditions by adjusting the number of individual workers engaged in the various tasks (Robinson 1992a, b; Johnson 2010). An example of this plasticity in DOL in honey bees is during periods of increasingly abundant and high-quality food, when foragers recruit additional foragers from among the most advanced MABs, including the undertakers.

For the undertaking task, it has been found that experimental increases in corpses in the colony resulted in more bees engaging in the task (Breed et al. 2002). Also, depleting the number of undertakers by removal of bees carrying corpses resulted in new bees taking up undertaking duties (Breed et al 2002). To date, it is unknown what will happen with corpse removal when the colony is exposed to a high parasite load, where increased bee mortality may enhance the stimuli for recruitment of undertakers due to the presence of more corpses. We can therefore expect that colonies will have more or more experienced undertakers, enabling them to remove corpses efficiently. However, at high parasite load in combination with high workload, the flexibility of DOL may be impaired (Van Dooremalen et al. 2018) limiting the amount of additional undertakers that can be recruited. Moreover, the performance of corpse removal could be impaired by a parasite-related reduction of the condition of worker bees (Janmaat et al. 2000; Van Dooremalen et al. 2013).

We compared corpse removal in colonies with a fieldrealistic exposure to the parasitic mite Varroa destructor $(\mathrm{V}+$ colonies) and colonies that were treated against this parasite (V-colonies). We experimentally added dead bees to the colonies of both groups to challenge the colony's task performance by increasing the demand for the corpse removal task. Exposure to V. destructor and related diseases is generally seen as one of the important stressors in honey bee colonies that can explain the annual losses in many countries (Le Conte et al. 2010; Van Dooremalen et al. 2018). V. destructor reduces the body weight and protein content of individual bees, which is found to shorten their lifespan (Van Dooremalen et al. 2012, 2013) and flight performance (Blanken et al. 2015). In this study, we tested whether undertakers of colonies exposed to high parasite load remove corpses faster when an elevated number of corpses is presented in the hive, compared to colonies with reduced parasite levels.

\section{Materials and methods}

\section{Experimental set-up}

From May 2015 to October 2015, 20 honey bee colonies (Apis mellifera spp.) were placed at an apiary at the organic farm Droevendaal of Wageningen University and Research, The Netherlands (51 $\left.{ }^{\circ} 59^{\prime} 32.35^{\prime \prime} \mathrm{N}, 5^{\circ} 39^{\prime} 46.81^{\prime \prime} \mathrm{E}\right)$. The colonies were housed in one or two storey hives (type "spaarkast", Simplex measures). Prior to the experiment, we randomly allocated colonies to the two treatment groups. From May 5th until July 3rd, we treated 10 colonies against $V$. destructor using Apistan (Vita Europe Ltd., no resistance against the active ingredient tau fluvalinate was observed within these colonies) and the other 10 colonies left untreated. This created a group with a low exposure to $V$. destructor ( $\mathrm{V}-$ colonies) and a group with a field-realistic, but high infestation ( $\mathrm{V}+$ colonies).

The colonies were visually checked at a monthly interval to establish colony status. This entailed the presence of brood in all stages and the presence of the queen. If a queen was found absent, it was replaced with a mated queen. Using the same monthly interval, the colonies were sampled to measure $V$. destructor infestation. Per colony, a sample of approximately $15 \mathrm{~g}$ of bees ( 120 bees) was scooped from an outer frame and stored in a freezer $\left(-20^{\circ} \mathrm{C}\right)$ until further use. The repeated sampling of a relatively low number of bees over a period of six months gives an accurate measure of the mite infestation, while not depleting the colonies of its bees (Van Dooremalen et al. 2018). By washing the samples, the number of mites and bees were obtained based on which the $V$. destructor infestation was calculated (Dietemann et al. 2013). We expressed the parasite load as number of mites per gram bees.

In preparation of the experiment, dead bees were obtained from other colonies and stored in the freezer $\left(-20^{\circ} \mathrm{C}\right)$ until further use (they were thawed prior to use). The dead bees were colour marked (Posca $\left.{ }^{\circledR}\right)$ on the thorax and abdomen to allow easy observation during the experiment. The corpse removal by the undertakers was investigated by placing marked dead bees on a removable mesh screen bottom board. Undertakers were challenged by a workload of either 25 or 100 dead bees. The removal of dead bees from the hive was observed at daytime by counting the remaining dead bees every $20 \mathrm{~min}$ after the start of the experiment for the first $180 \mathrm{~min}$, every $30 \mathrm{~min}$ for the next $120 \mathrm{~min}$ and every $60 \mathrm{~min}$ after that until $480 \mathrm{~min}$ had passed. If there were still dead bees left, a final check was performed at $24 \mathrm{~h}$ after the start of the experiment. During each observation, we counted the remaining bees and kept track when all bees were removed (referred to as end time). We defined undertaking performance as the number of corpses removed after fixed time intervals and the time until task completion.

We repeated the experiment seven times (referred to as "round" in the analysis: 1, 9, 30 August, 6, 13, 18 September and 4 October 2015). For each round, six colonies were randomly selected from the treatment groups (three for $\mathrm{V}+$ and three for $\mathrm{V}-$ ). The number of added corpses was attributed randomly as well, meaning that the undertakers in the colonies 
could have a different workload in one round compared to another. All colonies were used at least once during the experiment, but because the time intervals between measurements and the workload varied between rounds, it was assumed there was no or a negligible learning effect. As corpse removal may be impaired during bad weather conditions similar as foraging because both tasks involve flight activity and carrying loads (Vicens and Bosch 2000), we collected data on ambient temperature, wind speed, precipitation, humidity and relative sunshine duration from the nearby weather station Veenkampen $\left(51^{\circ} 58^{\prime} 55.1^{\prime \prime} \mathrm{N}, 5^{\circ} 37^{\prime} 36.3^{\prime \prime} \mathrm{E}\right)$.

\section{Statistical analysis}

The differences in varroa load between the $\mathrm{V}+$ and $\mathrm{V}$ - groups were tested for each month using linear mixed models (LMM). We included hive as random factor. The assumptions for normality of the residuals and sphericity were met using the lntransformed number of mites per gram bees.

We tested whether the number of removed dead bees at 20, 40, 100 and 480 min after introduction in the hive differed between the $\mathrm{V}+$ and $\mathrm{V}-$ groups using LMMS. The varroa treatment and the number of dead bees and their interaction were used as fixed factors. As we repeatedly used the same hives over the seven rounds, we included round as repeated variable and hive as subject variable in the LMMs. The number of removed dead bees was ln-transformed to meet the assumptions of normality of the residuals.

We also tested whether the time until the honey bees removed all dead bees differed between the varroa treatments. Therefore, we applied again LMMs with repeated measures (rounds) per hive. Here, the end time was used as dependent variable with the varroa treatment, the number of dead bees and their interaction as fixed factors, and hive and round as random factors. The time until removal of all dead bees was $1 n$-transformed to meet the assumptions of normality of the residuals.

For each LMM, we tested whether we had to use the restricted maximum likelihood (REML) or maximum likelihood (ML), depending on the lowest Akaike's information criterion (AIC) score. To compare the pairwise differences between the groups, we used the Tukey post hoc test after each LMM. Finally, we used Pearson correlation to test the relationships between the time until the honey bees removed all dead bees and the environmental variables. All analyses were done in R (version 3.6.2; R Core Team 2019).

\section{Results}

The $\mathrm{V}+$ colonies, which were not treated against mites, indeed contained a higher number of mites per gram bees compared to treated V-colonies (Fig. 1; LMM: Varroa
$\left.F_{1,17}=7.2, p=0.015\right)$. Mite infestation increased until October, samples of September onwards contained a higher number of mites per gram bees compared to earlier months (Month $F_{4,68}=0.8, p=0.488$ ), and even more so in $\mathrm{V}+$ colonies (Varroa $\times$ Month $F_{4,68}=2.9, \mathrm{p}=0.030$ ).

We found that at 20 and $40 \mathrm{~min}$ after adding the corpses to the colonies, $\mathrm{V}+$ colonies had removed more dead bees than $\mathrm{V}$ - colonies (Table 1, Fig. 2), and the undertakers in the colonies where 100 bees were added removed the highest number of dead bees. After 100 and $480 \mathrm{~min}$, almost all dead bees were removed from the hive, hence the small standard errors of the mean. Even though the difference between $\mathrm{V}+$ and $\mathrm{V}-$ colonies disappeared at $100 \mathrm{~min}, \mathrm{~V}+$ colonies used in total less time to remove 100 dead bees than $\mathrm{V}-$ colonies, whereas time until task completion and removal of all corpses did not differ between colonies when challenging them with either 25 or 100 dead bees (Table 1, Fig. 3).

We found significant correlations between the time until the honey bees removed all dead bees (ln-transformed, $n=84$ in all cases) and the mean ambient temperature (Pearson correlation $r=-0.246, p=0.024$ ) and wind speed (Pearson correlation $r=0.237, p=0.030$ ). These results suggest that bees use less time to remove all dead bees when temperatures are higher and wind speed is lower. We did not find a correlation with rainfall (Pearson correlation $r=0.008, p=0.946$ ), humidity (Pearson correlation $r=0.144, p=0.192$ ) and sunshine (Pearson correlation $r=-0.025, p=0.821$ ) probably because we only did the experiments on relatively sunny days without rainfall.

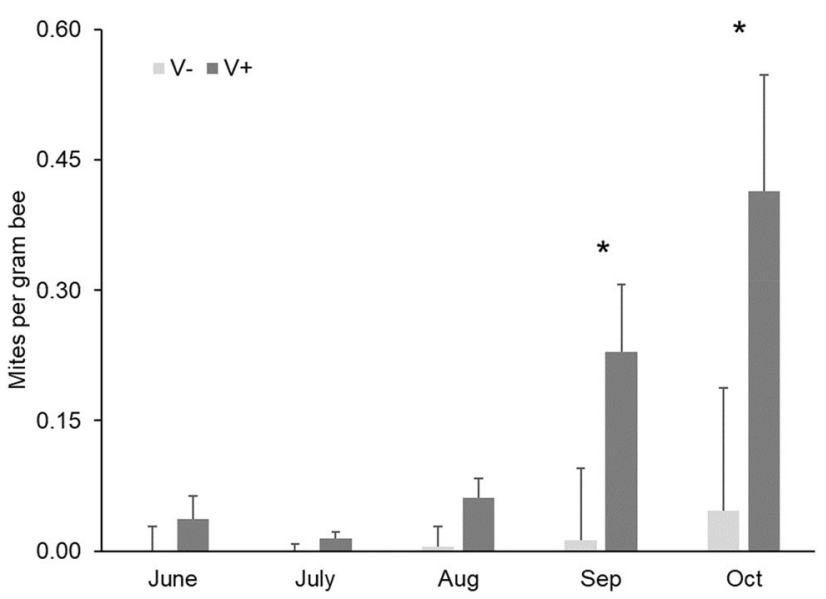

Fig. 1 Mean number of mites per gram bee for the $\mathrm{V}-$ and $\mathrm{V}+$ groups $(\mathrm{V}-$ is low varroa load and $\mathrm{V}+$ is high varroa load) per month. The error bars indicate the standard errors of the mean. The letters indicate significant differences between the groups based on a repeated measures general linear model that was followed by the Tukey post hoc test. The asterisk indicates significant differences between the $\mathrm{V}-$ and $\mathrm{V}+$ groups. Note that the statistics were done using the ln-transformed number of mites per gram bees (we added 0.05 to account for the 0 -values) 
Table 1 Results of the linear mixed models for the effects of the stressors Varroa destructor on the number of removed dead honey bees after 20, 40, 100 and $480 \mathrm{~min}$ for either 25 or 100 introduced dead honey bees, and on the time until the honey bees removed all dead bees

\begin{tabular}{|c|c|c|c|c|c|c|}
\hline \multirow[b]{2}{*}{ Independent variables } & \multirow[b]{2}{*}{ Statistics } & \multicolumn{4}{|c|}{ Minutes after introduction } & \multirow[t]{2}{*}{ Time all bees removed } \\
\hline & & 20 & 40 & 100 & 480 & \\
\hline \multirow[t]{2}{*}{ Dead bees } & $F$ & $14.7(1,64.6)$ & $18.4(1,64.3)$ & $41.9(1,67.3)$ & $3977.9(1,73.4)$ & $5.3(1,66.6)$ \\
\hline & $p$ & $<0.001$ & $<0.001$ & $<0.001$ & $<0.001$ & 0.024 \\
\hline \multirow[t]{2}{*}{ Varroa } & $F$ & $28.3(1,64.3)$ & $21.4(1,65.9)$ & $1.4(1,23.3)$ & $0.04(1,37.5)$ & $6.7(1,26.1)$ \\
\hline & $p$ & $<0.001$ & $<0.001$ & 0.256 & 0.826 & 0.015 \\
\hline \multirow[t]{2}{*}{ Dead bees $\times$ Varroa } & $F$ & $3.9(1,65.3)$ & $2.2(1,65.2)$ & $0.07(1,69.3)$ & $4.67(1,73.4)$ & $1.03(1,67.6)$ \\
\hline & $p$ & 0.052 & 0.144 & 0.794 & 0.033 & 0.313 \\
\hline Estimation & & REML & REML & REML & REML & REML \\
\hline
\end{tabular}

For each factor in the model, the $F$ - and $p$-values and the degrees of freedom (between brackets) are given. For each model, we give the applied method of estimation (REML restricted maximum likelihood). The sample sizes were 167 for the models for 25 dead bees and 168 for the models for 100 dead bees. The sample size was 84 for the time until the honey bees removed all dead bees. The results of the number of removed dead honey bees are illustrated in Fig. 2, and Fig. 3 shows the time until the honey bees removed all dead bees

\section{Discussion}

In this study, we tested whether undertakers of honey bee colonies exposed to high $V$. destructor load remove corpses faster when an elevated number of corpses is presented in the hive, compared to colonies with reduced parasite levels. When colonies are exposed to high $V$. destructor load, lifespan of honey bees decreases (Van Dooremalen et al. 2012), stimulating the demand for corpse removal. We found that in the first hour after introduction of the corpses, V+colonies acted faster compared to V-colonies, especially when challenged to remove 100 corpses. V+ colonies used less time until task completion, especially when challenged to remove 25 corpses. These results suggest that the performance of corpse removal is not likely to be impaired by a high parasite load in combination with high workload.

Corpse removal is a specialized task only performed by a small percentage of bees in a colony from a distinct genetic pool of subfamilies with a low threshold (Robinson and Page 1995; Trumbo et al. 1997). At the same time, the undertaking task has to compete with the demand for other tasks in a colony that require MABs (Sun and Zhou 2013). The rapid increase in corpse removal after corpse addition in our study corroborates with earlier findings (Robinson and Page 1995; Breed et al. 2002). The first efficient undertaking response in $\mathrm{V}+$ colonies may have been caused by more (Breed et al. 2002) or more experienced (Robinson and Page 1995) undertakers on standby compared to $\mathrm{V}$ - colonies, resulting in less total time needed to complete their undertaking task at increased workload. Experienced bees removed corpses faster than less experienced bees and also were less likely to drop corpses while exiting the hive (Trumbo and Robinson 1997). When more bees are recruited, the increased removal rate would support a response-threshold model for engagement of worker bees in task performance (Breed et al. 2002).
Both mechanisms may be involved in explaining increased corpse removal in our study, but were not further investigated as we did not mark individual undertakers.

Pathogens and parasites can alter the condition of individuals affecting task performance and task allocation in the colony (Natsopoulou et al. 2015). The effects are generally detrimental for individuals, for example, leading to a shorter life span and earlier task engagement. It is known that $V$. destructor can have physical and physiological consequences for individual worker bees infected during pupation (Amdam et al. 2004; Van Dooremalen et al. 2013). In turn, task performance is known to be negatively affected. Kralj and Fuchs (2006) showed that mortality rates of foragers were higher in highly infested colonies compared to less infested colonies. In this study, we did not look at individual consequences of $V$. destructor infestation on undertakers, and therefore, we cannot exclude the notion that infested workers might be outperformed by healthy kin. At colony level, however, the effect of $V$. destructor on corpse removal is positive.

It has been predicted that the colony's ability to respond to changing conditions is constrained due to strong genetic influences on task performance (Robinson and Page, 1995) as only few sub-families in the colony have low thresholds for engagement into the undertaking task and undertaking is a task that is less accessible via task-switching. However, independent of these potential genetic background differences, we found a strong stress response of the colonies rather than differences between the colonies within each group. Corpse removal increased in colonies under $V$. destructor-induced stress. Especially when challenged with a relatively high number of experimentally added corpses (i.e. $100)$, the colonies responded with immediately increased removal. Even though the $\mathrm{V}+$ colonies lost their advantage of increased corpse removal somewhere between 40 and 

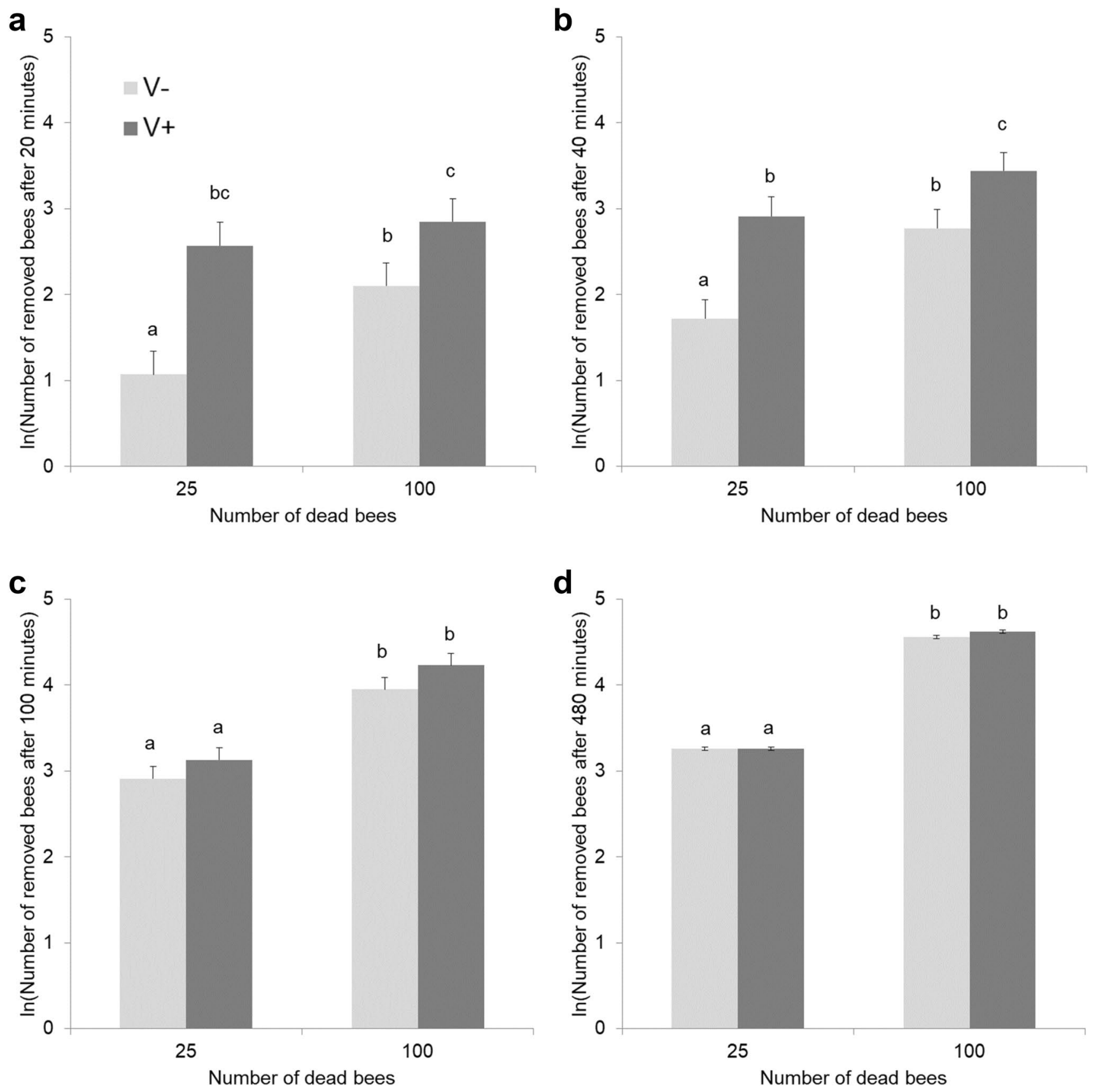

Fig. 2 Mean number of removed dead honey bees after a 20, b 40, c 100 and d 480 min for the varroa treatment (V- is low varroa load and $\mathrm{V}+$ is high varroa load) and the number of dead bees introduced to the colony (25 or 100). Each subsequent time step includes the data of the previous time steps. The error bars indicate the standard errors

$100 \mathrm{~min}, \mathrm{~V}+$ colonies used less total time when challenged to remove 100 corpses until task completion than $\mathrm{V}+$ colonies, suggesting that undertaking was not impaired for these offered challenges at our field-realistic parasite level. Our results support the hypothesis of Van Dooremalen et al. (2018) that colonies may well be able to compensate for sublethal negative effects of stressors on their individuals.

of the mean. The letters indicate significant differences between the groups based on a linear mixed model that was followed by the Tukey post hoc test. Note that the statistics were done using the ln-transformed number of mites per gram bees (we added 1 to account for the 0 -values)

This adaptive capacity is called social resilience (Van Dooremalen et al. 2018). Note that we cannot exclude long term effects for the colony, as time spent on undertaking cannot be spent on other tasks. Honey bee hygienic behaviour (i.e. removal of dead, diseased and mite-parasitize brood) is correlated with undertaking behaviour (Perez and Johnson 2019). As we did not measure the hygienic behaviour of 


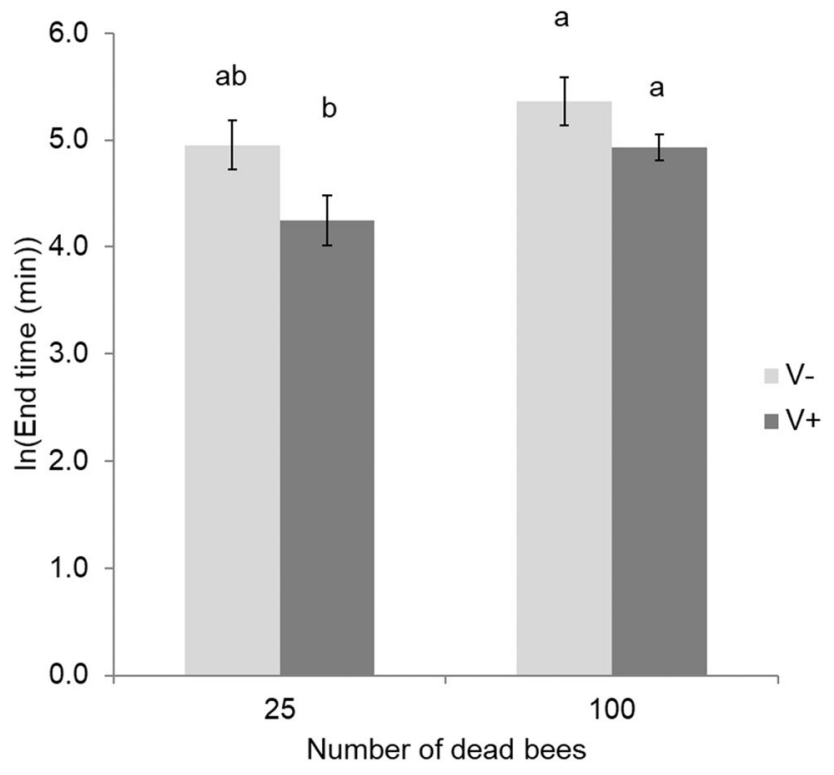

Fig. 3 Estimated marginal mean time until the honey bees removed all dead bees for the stressor Varroa destructor (note that the $y$-axis shows the ln-transformed values). The error bars indicate the standard errors of the mean. $\mathrm{V}-$ represents the colonies with low varroa load, whereas $\mathrm{V}+$ the colonies with high varroa load. The letters indicate significant differences based on a linear mixed model that was followed by the Tukey post hoc test

our colonies, we cannot test whether more hygienic colonies remove corpses faster. This is an interesting question for colonies with elevated hygienic behaviour; see, for example, Panziera et al. (2017).

Our findings of the experiment of adding corpses suggest that workers compensate immediately after emergencies or when labour is required for task changes (Breed et al. 2002), whereas this immediate increase in removal excludes a waiting period until new, specialized workers reach the appropriate age. These findings give insight into how DOL is regulated under stress in eusocial insect colonies such as honey bees (Sendova-Franks and Franks 1994; Van Dooremalen et al. 2018). Probably immediate demands for labour such as after emergencies require different mechanisms of worker allocation than DOL determinants as age (Seeley 1982), such as endocrine influences (Robinson and Page 1989), genetic differences among workers (Robinson and Page 1988; Breed and Rogers 1991), or a combination of these factors (Robinson 1992a, b; Robinson et al. 1992). Our paper contributes to understanding social resilience in colonies under high stress and exposed to immediate emergencies as our findings suggest that increased stimuli (higher dead bee supply) result in improved undertaking performance.

Author contributions FL, FK, CD and BC conceived this research and designed experiment; FK collected the data; FL analysed the data;
FL, BC and CD wrote the paper. All authors revised and approved the final manuscript.

Funding This project was funded from 2013 to 2015 by the Ministry of Economic Affairs (EZ, currently LNV) of The Netherlands 20142015 (BO-20-003-024). Vita Europe Ltd. kindly provided Apistan.

Availability of data and material Data supporting this article can be found at the 4TU. ResearchData repository (https://doi. org/10.4121/13181402.v1).

\section{Compliance with ethical standards}

Conflicts of interest The authors declare that they have no conflict of interest.

Open Access This article is licensed under a Creative Commons Attribution 4.0 International License, which permits use, sharing, adaptation, distribution and reproduction in any medium or format, as long as you give appropriate credit to the original author(s) and the source, provide a link to the Creative Commons licence, and indicate if changes were made. The images or other third party material in this article are included in the article's Creative Commons licence, unless indicated otherwise in a credit line to the material. If material is not included in the article's Creative Commons licence and your intended use is not permitted by statutory regulation or exceeds the permitted use, you will need to obtain permission directly from the copyright holder. To view a copy of this licence, visit http://creativecommons.org/licenses/by/4.0/.

\section{References}

Amdam GV, Hartfelder K, Norberg K, Hagen A, Omholt SW (2004) Altered physiology in worker honey bees (Hymenoptera: Apidae) infested with the mite Varroa destructor (Acari: Varroidae): a factor in colony loss during overwintering? J Econ Entomol 97:741-747

Blanken LJ, van Langevelde F, van Dooremalen C (2015) Interaction between Varroa destructor and imidacloprid reduces flight capacity of honeybees. Proc R Soc B 282:20151738

Boecking O, Spivak M (1999) Behavioral defenses of honey bees against Varroa jacobsoni Oud. Apidologie 30:141-158

Bonabeau E, Theraulaz G, Deneubourg JL (1996) Quantitative study of the fixed threshold model for the regulation of division of labour in insect societies. Proc R Soc Lond B 263(1376):1565-1569

Breed MD, Rogers KB (1991) The behavioral genetics of colony defense in honeybees: genetic variability for guarding behavior. Behav Genet 21:295-303

Breed MD, Robinson GE, Page RE (1990) Division of labor during honey bee colony defense. Behav Ecol Sociobiol 27(6):395-401

Breed MD, Williams DB, Queral A (2002) Demand for task performance and workforce replacement: undertakers in honeybee, Apis mellifera, colonies. J Insect Behavior 15(3):319-329

Dietemann V, Nazzi F, Martin SJ, Anderson DL, Locke B, Delaplane KS, Wauquiez Q, Tannahill C, Frey E, Ziegelmann B, Rosenkranz P (2013) Standard methods for varroa research. J Apic Res 52(1):1-54

Duarte A, Pen I, Keller L, Weissing FJ (2012) Evolution of selforganized division of labor in a response threshold model. Behav Ecol Sociobiol 66(6):947-957 
Evans JD, Spivak M (2010) Socialized medicine: individual and communal disease barriers in honey bees. J Inv Path 103:S62-72

Janmaat AF, Winston ML, Ydenberg RC (2000) Condition-dependent response to changes in pollen stores by honey bee (Apis mellifera) colonies with different parasitic loads. Behav Ecol Sociobiol 47:171-179

Johnson BR (2010) Division of labor in honeybees: form, function, and proximate mechanisms. Behav Ecol Sociobiol 64:305-316

Kralj J, Fuchs S (2006) Parasitic Varroa destructor mites influence flight duration and homing ability of infested Apis mellifera foragers. Apidologie 37:577-587

Kruitwagen A, van Langevelde F, van Dooremalen C, Blacquière T (2017) Naturally selected honey bee (Apis mellifera) colonies resistant to Varroa destructor do not groom more intensively. $\mathrm{J}$ Apic Res 56:354-365

Le Conte Y, Ellis M, Ritter W (2010) Varroa mites and honey bee health: can Varroa explain part of the colony losses? Apidologie 41:353-363

Moore AJ, Breed MD, Moor MJ (1987) The guard honey bee: ontogeny and behavioral variability of workers performing a specialized task. Anim Behav 35:1159-1167

Natsopoulou ME, McMahon DP, Doublet V, Bryden J, Paxton RJ (2015) Interspecific competition in honeybee intracellular gut parasites is asymmetric and favours the spread of an emerging infectious disease. Proc R Soc B 282(1798):20141896

Panziera D, Van Langevelde F, Blacquière T (2017) Varroa sensitive hygiene contributes to naturally selected varroa resistance in honey bees. J Apic Res 56:635-642

Perez AA, Johnson BR (2019) Task repertoires of hygienic workers reveal a link between specialized necrophoric behaviors in honey bees. Behav Ecol Sociobiol 73:123

R Core Team 2019. R: a language and environment for statistical computing. Vienna, Austria: R Foundation for Statistical Computing

Robinson GE (1992a) Regulation of division of labor in insect societies. Annu Rev Entomol 37(1):637-665

Robinson GE (1992b) Regulation of division of labor in insect societies. Annu Rev Entomol 37:637-665

Robinson GE, Page RE Jr (1988) Genetic determination of guarding and undertaking in honeybee colonies. Nature 333:356-358

Robinson GE, Page R (1989) Genetic basis for division of labor in an insect society. In: Breed MD, Page RE (eds) The Genetics of social evolution. Westview Press, Boulder, pp 61-80

Robinson GE, Page RE Jr (1995) Genotypic constraints on plasticity for corpse removal in honey bee colonies. Anim Behav 49:867-876
Robinson GE, Page RE, Strambi C, Strambi A (1992) Hormonal and genetic control of behavioral integration in honey bee colonies. Science 246:109-112

Rueppell O, Hayworth MK, Ross NP (2010) Altruistic self-removal of health-compromised honey bee workers from their hive. J Evol Biol 23(7):1538-1546

Seeley TD (1982) Adaptive significance of the age polyethism schedule in honeybee colonies. Behav Ecol Sociobiol 11:287-293

Sendova-Franks AB, Franks NR (1994) Social resilience in individual worker ants and its role in division of labour. Proc R Soc B 256:305-309

Sun Q, Zhou X (2013) Corpse management in social insects. Int J Biol Sci 9(3):313

Trumbo ST, Robinson GE (1997) Learning and task interference by corpse-removal specialists in honey bee colonies. Ethology 103:966-975

Trumbo ST, Huang ZY, Robinson GE (1997) Division of labor between undertaker specialists and other middle-aged workers in honey bee colonies. Behav Ecol Sociobiol 41(3):151-163

Van Dooremalen C, Gerritsen L, Cornelissen B, van der Steen JJM, van Langevelde F, Blacquière T (2012) Winter survival of individual honey bees and honey bee colonies depends on level of Varroa destructor infestation. PLoS ONE 7:e36285

Van Dooremalen C, Stam E, Gerritsen L, Cornelissen B, van der Steen JJM, van Langevelde F, Blacquière T (2013) Interactive effect of reduced pollen availability and Varroa destructor infestation limits growth and protein content of young honey bees. J Insect Physiol 59:487-493

Van Dooremalen C, Cornelissen B, Poleij-Hok-Ahin C, Blacquière T (2018) Single and interactive effects of Varroa destructor, Nosema spp., and imidacloprid on honey bee colonies (Apis mellifera). Ecosphere 9:02378

Vicens N, Bosch J (2000) Weather-dependent pollinator activity in an apple orchard, with special reference to Osmia cornuta and Apis mellifera (Hymenoptera: Megachilidae and Apidae). Environ Entomol 29(3):413-420

Visscher PK (1983) The honey bee way of death: necrophoric behavior in Apis mellifera. Anim Behav 31:1070-1076

Wilson-Rich N, Spivak M, Fefferman NH, Starks PT (2009) Genetic, individual and group facilitation of disease resistance in insect societies. Annu Rev Entomol 54:405-423 